\title{
WHICH VISUALISATION TOOLS AND WHY? COMPARING PERCEPTIONS OF STUDENT AND PRACTICING DESIGNERS TOWARD DIGITAL SKETCHING
}

\author{
Charlie RANSCOMBE ${ }^{1}$, Katherine BISSETT-JOHNSON ${ }^{1}$, Wenwen ZHANG ${ }^{2}$, Boris \\ EISENBART ${ }^{1}$ and Carlye LAUFF ${ }^{3}$ \\ ${ }^{1}$ Swinburne University of Technology, Australia \\ ${ }^{2}$ University of Canterbury, New Zealand \\ ${ }^{3}$ SUTD-MIT International Design Centre, Singapore
}

\begin{abstract}
Different design tools offer a variety of different benefits to designers at different stages in the design process. Yet, as digital design tools develop, providing more nuanced utility, we observe a challenge for design educators in teaching as per both how and when to apply said tools. This paper contributes to the discussion around digital tools in design education by comparing student perceptions of digital sketching with those of practicing designers. We do so from the perspective of the characteristics of digital sketching that are referenced by participants when describing its application in a typical design process. Results show how characteristics relating to representation of ideas and usability are widely referenced by both groups; however, we found a difference in practicing designers' referencing of time characteristics more so than students. Based on this difference in the way digital sketching is perceived, we conclude that greater consideration how different tools influence the time taken to create a visualisation, and thus speed of iteration, is the key to educating students on how to consider and select different design tools.
\end{abstract}

Keywords: Sketching, computer aided design (CAD), visualisation, communication, design tools, digital sketching

\section{INTRODUCTION}

There is a wide array of visualisation tools available to designers in industrial and engineering design disciplines (sketching, 3d modelling, prototyping, VR/AR) [1]. As computing technology advances at an ever-rapid pace, so too does the capability and breadth of applications for digital tools in the design process. Well established visualisation tools such as traditional sketching and CAD have been studied as to how their characteristics can influence designers thinking and hence their optimal use during the design process [2-4]. From the perspective of design education these tools have also been researched with one major trend being highlighted, that students are seduced by more high-tech tools that offer visualisations with greater levels of detail and realism. Thus, the selection of digital tools over lower fidelity tools such as sketching leads to a corresponding negative impact on design thinking [5-7].

Given the trend in students' preference for ever more high-tech tools combined with the unrelenting advances and sophistication in digital design tools, there is a need to research the perceptions of students towards selection and use of digital design tools within the design process. Hence this paper investigates differences in perceptions of using digital sketching (as an example of a relatively new/emerging visualisation tool) between practicing designers and student designers. In doing so we aim to improve our understanding of how the different characteristics of digital sketching inform its use within the design process. In turn we believe this can provide insights on how we educate students with respect to selecting and using digital sketching and in turn other emerging visualisation tools. The following section gives a background to digital tools in design education and explains our approaches to characterise design tools. Our research method is set out in Section 3, with results given in Section 4 which are discussed, and conclusions drawn in Section 5. 


\section{BACKGROUND}

As a background to our study we will first summarise extant literature on the topic of digital design tools in design education providing a basis for the study and the subsequent review of the different characteristics of visualisation tools.

\subsection{Digital design tools in education}

As stated in the previous section, a body of research exists exploring the role of visualisation tools within the design process, including student use (or lack of) different tools. Traditional sketching is routinely flagged as a critical visualisation tool for designers to embody ideas as well as communicate ideas to others $[8,9]$, citing speed and opportunity for reflection and reinterpretation as key characteristics. Yet, research in design education shows that despite positive characteristics, concerns around inhibition mean students often do not engage easily with this tool $[6,7]$. Instead students prefer more advanced digital visualisation tools that offer greater resolution and visual aesthetic which can have negative impact on creativity and breadth of ideas explored [5,6].

Among the breadth of new visualisation tools referred to in the Introduction is digital sketching. While the concept of digital sketching is not particularly new, recent decreasing costs of digital sketching hardware, increased computational power. and integration of sketch input in 3d modelling software has seen its use rise in industry and cemented its presence in design education. Recent research into digital sketching suggests that it embodies a form of hybrid visualisation tool offering some of the complementary characteristics of traditional sketching (speed and reinterpretation) and CAD (detail and aesthetics), hence mitigating some of the issues highlighted above [10]. Thus, digital sketching is the focus of this paper as we contend it is an example of new type of design tool. Furthermore, we believe it is important to study with findings informing design education's approach to incorporating more recently emerging design tools into design education.

\subsection{Characterising design tools}

While digital sketching is the focus of our study, the purpose is to provide insights on tool use that can be generalised beyond digital sketching to the study other emerging tools. To do so we require a means to characterise design tools in a generalised way. Extant literature into design processes [11], visualisation $[12,13]$ and prototyping offer various approaches $[14,15]$. However, many of these studies focus on a tool or perspective such as affordances of tools or are without the context of the user's capability. Most recently, Zhang, Ranscombe [1] synthesised the literature to present an exhaustive framework of generalised design tool characteristics, which can be used as the basis to compare the substantially different tools (sketching and CAD). Hence, it is adopted in this study as the best means to understand perceptions generalised manner (See Table 1). For brevity we refer the reader to the original text for full explanation and details of the framework.

\section{METHOD}

Our approach to collect data on student and practicing designers' perceptions of digital sketching is outlined below. This is followed by our approach to analysis, explaining how referencing of design tool characteristics forms the basis for comparison of perceptions of digital sketching.

\subsection{Data collection}

Student perceptions were gathered as part of a visualisation course taught to postgraduate students undertaking a Master of Design degree. Perceptions were captured in the context of a 7-week design/visualisation project where the objective was to create concepts for a household appliance (a pod coffee machine). This project was selected as the basis for analysis as it reflects a typical design activity (i.e. ideation and concept design) in which digital sketching is used. Data was collected using a diary method as used in comparable studies [16-18]. The diary method was selected on the basis that it facilitates capturing data for many students at various points throughout their design process. Diary entries were recorded by students as part of a design project portfolio that students submitted at the end of the project. Diary entries were expected to be made throughout the project at weekly intervals. Within each entry students were prompted to reflect on the use of digital sketching to visualise and develop their ideas. A total of 79 student diaries was collected over 3 consecutive deliveries of the project. 
Data collection for practitioners, forming the comparison data set was less straightforward to collect. Due to concerns about intellectual property and time constraints, it was not possible to acquire equivalent diary entries from practitioners. As an alternative, an interview method was adopted. The rationale for using interview was, to capture comparable perceptions (or recollections) over the duration of a design project despite only having one occasion to question designers. 11 practitioners from 3 engineering and design firms were interviewed. Each interview lasted approx. 60 mins. The interview was semistructured using the same prompts as the student diaries on their experience with digital sketching. Participants were asked to base their responses to questions on recent design projects that they felt were representative of their typical design activities.

\subsection{Data Analysis}

Both diary and interview data were coded following a scheme derived from Zhang, Ranscombe [1] framework to compare visualisation tools discussed in section 2.2. This facilitated the ability to translate/understand perceptions in terms of tool characteristics, and in turn generated generalisable impressions of perceptions for comparison. Coding using this framework of characteristics was conducted by analysing statements by practicing designers and diary entries by students for references to characteristics described in the framework. Reliability of coding was achieved by using two independent coders and checking for agreement.

Trial coding of student diary entries showed a high level of disagreement between coders. Subsequent attempts to resolve disagreement highlighted that the brevity of many student diary entries caused a high level of ambiguity and hence inability to reach consensus. In response, an alternate approach to coding was undertaken. The full framework was split into five higher level themes using the definitions of each characteristic. For example, while there was disagreement in coding Ambiguity, Fidelity and Level of Detail, coders agreed that statements of this type could be coded at a higher level as Representation characteristics. The full list of characteristics and grouping is included in Table 1. Subsequent trial coding using this higher-level coding scheme achieved a suitable level of intercoder reliability. Following coding, the number or references to each category of tool characteristics was recorded as the basis for analysis.

Table 1. Categories of Design Tool Characteristics used for coding data

\begin{tabular}{|c|c|c|c|c|c|}
\hline $\begin{array}{l}\text { High Level } \\
\text { Themes }\end{array}$ & Communication & Design Thinking & Representation & Time & Usability \\
\hline $\begin{array}{c}\text { Framework of } \\
\text { Visualisation } \\
\text { Tool } \\
\text { Characteristics } \\
\text { [1] }\end{array}$ & $\begin{array}{c}\text { External } \\
\text { Communication } \\
\text { Internal } \\
\text { Communication }\end{array}$ & $\begin{array}{c}\text { Lateral } \\
\text { Transformation } \\
\text { Problem Re-Framing } \\
\text { Vertical } \\
\text { Transformation }\end{array}$ & $\begin{array}{c}\text { Accuracy } \\
\text { Ambiguity } \\
\text { Amount of } \\
\text { Representation } \\
\text { Fidelity } \\
\text { Holistic view of Object } \\
\text { Level of Aesthetics } \\
\text { Level of Details }\end{array}$ & $\begin{array}{c}\text { Learning } \\
\text { Cost }\end{array}$ & $\begin{array}{c}\text { Compatibility } \\
\text { Flexibility } \\
\text { Immediacy } \\
\text { Mobility }\end{array}$ \\
\hline
\end{tabular}

Statements were further coded as to whether each characteristic is mentioned in a positive or negative statement. On further inspection of data, positive and negative was difficult to code. This was because references to characteristics were conditional, for example, the level of detail provided by digital sketching can be considered beneficial in one condition but a hinderance in another. For the purposes of this paper we were primarily interested in the referencing of characteristics, and thus the contextual positive/negative will become the subject of further research. 


\section{RESULTS}

The following results are presented in terms of the number of statements referring to different design tool characteristics as listed in Table 1. References to characteristics are presented as a proportion of the total number of statements coded (both in diaries and interviews). As such we compared students' and practitioners' perceptions of digital sketching in terms of the characteristics most referenced when describing the use of digital sketching. Figure 1 presents the proportion of characteristics referenced by each group. An overview of characteristics referenced by students is given in section 4.1, and practicing designers in section 4.2, with comparisons then made in section 4.3.

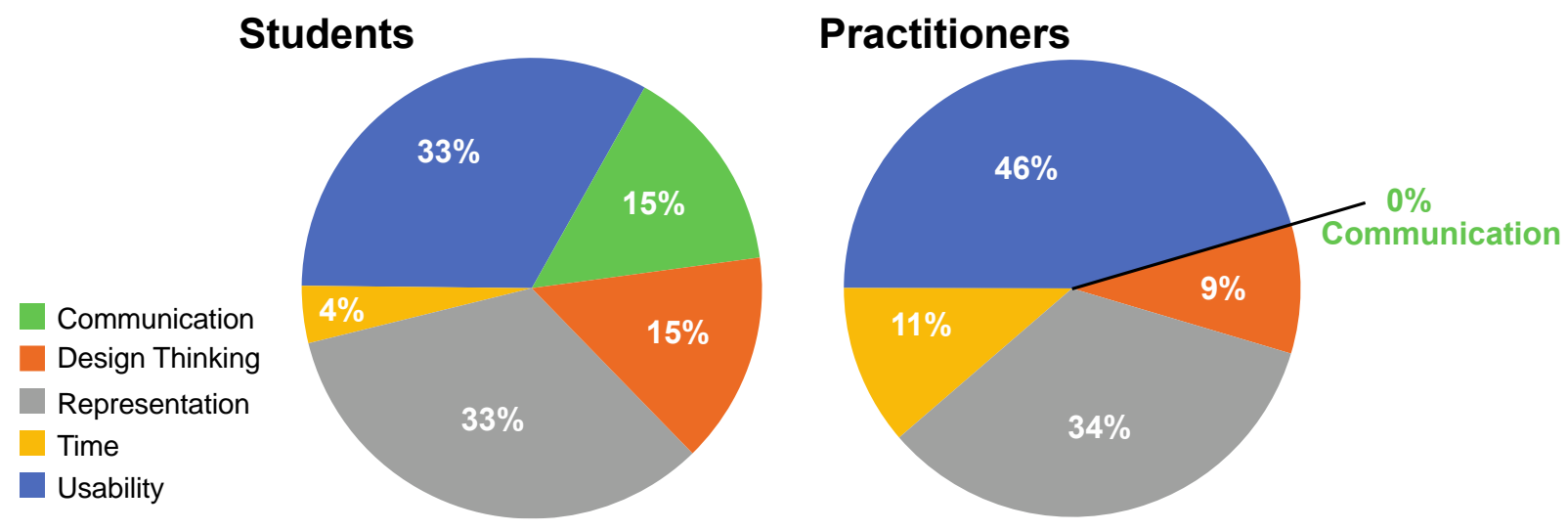

Figure 1. Comparing design tool characteristics referenced by students versus practitioners

\subsection{Student perceptions}

Tool characteristics relating to Representation and Usability make up the highest proportion of characteristics referenced (see Figure 1). Next Communication and Design Thinking characteristics are mentioned at an equal proportion of $15 \%$ respectively. Time characteristics are mentioned the least frequently, comprising $4 \%$ of responses. Based on these proportions, we infer that for students, Usability and Representational characteristics dominate their perception of digital sketching.

\subsection{Practitioner perceptions}

Like student responses, practitioners reference Usability and Representational characteristics most frequently with these characteristics making up approximately $80 \%$ of tool descriptions. Next, Time characteristics are described in $11 \%$ of responses and Design Thinking characteristics at $9 \%$. Notably Communication characteristics are not referenced at all.

\subsection{Comparing students' perceptions to practitioners' perceptions}

Comparing respective data for students and practitioners, similarity between the groups can be seen in their frequent referencing of Representation characteristics and Usability characteristics. The relatively large proportion of Representation characteristics (approx. one third of responses) is perhaps not surprising. It could be argued that the primary objective of any design visualisation is to represent potential ideas. Thus, it is expected that characteristics relating to this objective (or that describe the manifestation of visualisation) feature heavily in responses of both groups.

The greatest difference between student and practitioner perspectives is the lack of reference by Practitioners to Communication characteristics. We contend this could be explained by practitioners considering communication characteristics as obvious and/or implied when discussing visualisation. From another perspective, it is unlikely that practitioners do not consider communication whatsoever with respect to characteristics of visualisation tools. Nevertheless, this finding is subject to further analysis to be conducted soon.

The next biggest difference between data sets is in referencing of Time characteristics, $4 \%$ by students and $11 \%$ practitioners. While the proportion of references is relatively low, the difference in the number of references is almost threefold. Further discussion of this difference is given in the following section. Finally, we note there is a small difference in the proportion of Design Thinking characteristics referenced in both student and practitioner data sets (15\% and 9\% respectively). As with Communication characteristics, it is possible the relatively low level of referencing this characteristic by both groups 
stems from digital sketching being used to "design" and therefore its connection to design thinking is implied not explicitly expressed.

\section{DISCUSSION AND CONCLUSION}

Beyond the lack of reference to Communication characteristics, we contend the difference in perception of digital sketching with respect to Time characteristics is most interesting. All practicing designers' references to Time characteristics are made in the context of time spent to create a visualisation. Furthermore, statements were also interlinked with references to different Usability characteristics. The following statement by a practitioner exemplifies this connection between usability and time characteristics, "...you can have layers, you can go in and edit it and then if we actually decided that we want to change that design detail, 'can we try three different handles?', you can just do that digitally over the top, or save up copies, or even have different layers to turn on and off in Digital Sketching. So, it's much faster to do iterative work or refinement work (in Digital Sketching)". In contrast, student references to Usability revolve around ease or difficulty but without reference to Time characteristics. For example, "After practicing using a Photoshop [sketching] tools, my skill with Photoshop is getting better and more comfortable which makes my work tidier."

This difference in perceiving Time characteristics concurs with research on the skills of novice versus expert designers. It is known that iteration is a critical part of developing knowledge toward a solution [19] but moreover, that expert designers put emphasis on iterating quickly and frequently while novice designers are solution focused iterating less frequently within a solution [20,21]. This is reflected in our results where practicing designers talk about tools with consideration of time taken for iteration while students talk about tools with respect to representing/developing. Educating students in visualisation inherently focuses on mastery skills, i.e. accurately and fluently sketching ideas, or learning CAD software. Thus, it is not surprising that students emphasise Representation characteristics which are often the benchmark of how well they have mastered skills (and we assume closely related to final grades), with less consideration of time taken. Consequently, our overarching conclusion for design educators, is that there is a need to blend considerations of mastery of visualisation tools with the underlying theory of how different visualisation tools are purposed within the design process. Hence, we propose that in addition to mastering tools, students should be learning how to select the best tool for different stages of the design process. Based on the data from practicing designers, we also conclude the design tool selection process should be explained to students based on tools offering appropriate fidelity, iterative exploration, validation and communication of design intent. Highlighting the importance of Time characteristics in the context of iterating, might be a means to address the issue of students' preference for high-tech and high realism design tools. Thus, with respect to the development of new and emerging tools, we lastly conclude that Time characteristics, linked with facilitating iteration in the design process, are important to develop alongside Representational and Usability characteristics, which are usually at the fore when new visualisation tools are released.

A key limitation to findings of this study stems from the use diary method to collect student data versus interviews with practitioners. As noted in Section 3, the brevity of many diary entries meant that a higher resolution analysis using the full framework of design tool characteristics was not possible. Hence further research will conduct interviews with students to enable richer analysis of their perception of digital sketching. While findings offer insights that might be applicable to other visualisation tools, there would also be value in expanding this study to other tools both established and emerging, which in turn enables comparison of perceptions across tools as well as students and practitioners.

\section{REFERENCES}

[1] Zhang, W., et al., "Creation of a framework of design tool characteristics to support evaluation and selection of visualisation tools", in $22^{\text {nd }}$ International Conference on Engineering Design (ICED). 2019: Delft, Netherlands.

[2] Lawson, B., "CAD and creativity: does the computer really help?" Leonardo, 2002. 35(3): p. 327-331.

[3] Self, J.A., "CAD Tools and Creative Design, Grounds for Divorce or Match Made in Heaven?" CAD/CAM Review, 2013. 19(2): p. 36-43.

[4] Tsai, G. and Yang, M.C. "How It Is Made Matters: Distinguishing Traits of Designs Created by Sketches, Prototypes, and CAD." in ASME 2017 International Design Engineering Technical 
Conferences and Computers and Information in Engineering Conference. 2017. American Society of Mechanical Engineers.

[5] Robertson, B. and Radcliffe, D "Impact of CAD tools on creative problem solving in engineering design." Computer-Aided Design, 2009. 41(3): p. 136-146.

[6] Thurlow, L. and Ford, P.B. "Where have all the ideas gone? An anatomy of sketch inhibition among student designers". 2017. Design Research Society.

[7] van Passel, P. and Eggink, W. "Exploring the influence of self-confidence in product sketching". in 15th International Conference on Engineering and Product Design Education: Design Education-Growing our Future. 2013.

[8] Goldschmidt, G., "The dialectics of sketching”. Creativity research journal, 1991. 4(2): p. 123143.

[9] Lawson, B., "How designers think: The design process demystified". 2006, Oxford: Architectural Press.

[10] Ranscombe, C., et al. "Digital Sketch Modelling: Proposing a Hybrid Visualisation Tool Combining Affordances of Sketching and CAD”. in Proceedings of the Design Society: International Conference on Engineering Design. 2019. Cambridge University Press.

[11] Purcell, A. and Gero, J.S. "Drawings and the design process: A review of protocol studies in design and other disciplines and related research in cognitive psychology". Design studies, 1998. 19(4): p. 389-430.

[12] Pei, E. Campbell, I. and Evans, M. “A taxonomic classification of visual design representations used by industrial designers and engineering designers". The Design Journal, 2011. 14(1): p. 6491.

[13] Self, J., Dalke, H. and Evans, M. "Industrial Design Tools and Design Practice: An approach for understanding relationships between design tools and practice”. 2009.

[14] Camburn, B., et al., "Design prototyping methods: state of the art in strategies, techniques, and guidelines". Design Science, 2017. 3.

[15] Mathias, D., et al. "Characterising the affordances and limitations of common prototyping techniques to support the early stages of product development”. in DS92: Proceedings of the DESIGN 2018 15th International Design Conference. 2018.

[16] Badke-Schaub, P. and Frankenberger, E. "Analysis of design projects". Design Studies, 1999. 20(5): p. 465-480.

[17] Evans, M.A., et al., "Digital sketching and haptic sketch modelling during product design and development". 2015.

[18] Pedgley, O., "Capturing and analysing own design activity”. Design studies, 2007. 28(5): p. 463483.

[19] Adams, R.S. and Atman, C.J. "Characterizing engineering student design processes: An illustration of iteration”. Am Soc Eng Educ, 2000: p. 1-11.

[20] Smith, R.P. and Leong, A. "An observational study of design team process: A comparison of student and professional engineers". 1998.

[21] Wynn, D.C. and Eckert, C.M. "Perspectives on iteration in design and development. Research in Engineering Design”, 2017. 28(2): p. 153-184. 